\title{
Can Hematological Parameters be Used for Differential Diagnosis in Rotavirus Infection at any Age of Children? A 6-year Outcomes from a Tertiary Referral Center
}

\author{
๑ Meliha Aksoy Okan, ๑ Hayrettin Temel, ๑ Mesut Okur, ๑ Ayse Istanbullu Tosun* \\ Medipol University Faculty of Medicine, Department of Pediatrics, Istanbul, Turkey \\ *Medipol University Faculty of Medicine, Department of Microbiology, Istanbul, Turkey
}

Abstract

\begin{abstract}
Aim: Routine blood parameters are widely used to detect of infectious diseases. Our study aimed to investigate the hematological parameters changes in rotavirus (RV) acute gastroenteritis and to evaluate the value of these parameters in children.

Methods: In our study, the hematological data of patients diagnosed with RV-positive acute gastroenteritis (RPAGE) and RV-negative acute gastroenteritis (RNAGE) were analyzed between 2015-2020. In addition to the data automatically measured by complete blood count, lymphocyte/monocyte ratio (LMR), neutrophil/lymphocyte ratio (NLR), mean platelet volume/platelet ratio (MPVPR) were calculated. All cases were evaluated in three different age groups (<1-year-old, 1-to 5-year-old, and >5-year-old).

Results: The present study included 2,144 patients (340 children with RPAGE, 1,804 children with RNAGE). Red blood cell count, hemoglobin, and hematocrit were higher in cases over 1 year of age with RPAGE. The MPVPR was lower in all age groups with RPAGE. The cut-off values of MPVPR for predicting Rotavirus infection (RI) were 0.023 (<1-year-old group), 0.026 (1-to 5-year-old group), and 0.032 (>5-year-old group). The LMR was lower and NLR was higher in cases over 1 year of age with RPAGE. The cut-off value of LMR for predicting RI were 1.99 (1-to 5-year-old group) and 0.96 (>5-year-old group). The cut-off value of NLR for predicting RI were 1.41 (1-to 5-year-old group), and 3.79 (>5-year-old group).
\end{abstract}

Conclusion: The low MPVPR can be used as a hematological biomarker for the identification of RPAGE cases in all age groups. Low LMR and high NLR can indicate RPAGE cases in over 1 year of age.

Keywords: Gastroenteritis, rotavirus, neutrophils, lymphocytes, monocytes, mean platelet volume, platelets

\section{Introduction}

Diarrhea is the major leading cause of death among children younger than 5-year old worldwide (1). Rotavirus (RV) is one of the most common causes of acute gastroenteritis (AGE) in childhood and the leading worldwide cause of acute diarrhea-related death in children under the age of five $(2,3)$. RV-associated annual morbidity rates among children under five years of age ranged from 0 to $112 / 100,000$ with an average mortality rate of 39/10,000 per year in The Eastern Mediterranean region, as defined by the World Health Organization (WHO-EMRO region) (4). Deaths from rotavirus infection (RI) still continue despite efforts to make better hygiene conditions, widespread vaccination, and improvements in treatments $(5,6)$.

Rotaviruses belong to the Reovirus family, usually, type A RV is responsible for infections in children. Apart from $\mathrm{RV}$, the other most common causes of AGE in childhood are Noroviruses, enteric types of the adenovirus, and astroviruses (7). The diagnosis of $\mathrm{Rl}$ depends on the detection of RV antigen in stool by serological methods.

Address for Correspondence: Meliha Aksoy Okan, Medipol University Faculty of Medicine, Department of Pediatrics, Istanbul, Turkey Phone: +90 2124607777 E-mail: melihaaksoy@hotmail.com ORCID: orcid.org/0000-0002-8044-4992 Received: 10.05.2021 Accepted: 30.05.2021 
However, these tests can often be time-consuming, sometimes expensive and inaccessible. Routine complete blood count $(C B C)$ test is performed in pediatric patients, especially in many febrile diseases, because of its easy availability and cheaper.

In recent years, in addition to routine $C B C$ parameters, new hematological markers such as lymphocyte/monocyte ratio (LMR), neutrophil/lymphocyte ratio (NLR), mean platelet volume/platelet ratio (MPVPR) have been used in inflammation $(8,9)$.

This study aimed to evaluate the routine blood parameters in children with $A G E$ and investigate the easily accessible new hematological markers to use in the differential diagnosis of RI.

\section{Methods}

\section{Study Design}

The present study was approved by the Local Ethics Committee of Medipol University Hospital (approval no: 957/2020) and designed as a cross-sectional study which is one of the types of observational studies. Children with AGE aged 0 to 16 years who presented at the department of pediatrics from January 2015 to December 2020 were included in this study. Medical information for demographic data and laboratory parameters were extracted from patient files.

During the study period, RV antigen test was performed in 5,134 children with gastrointestinal complaints and in 831 of these patients (16.2\%) RV antigen was detected in the stool. In the present study, 340 children with RVpositive acute gastroenteritis (RPAGE), 1,804 children with RV-negative acute gastroenteritis (RNAGE) were included. The patients without hematological data were excluded

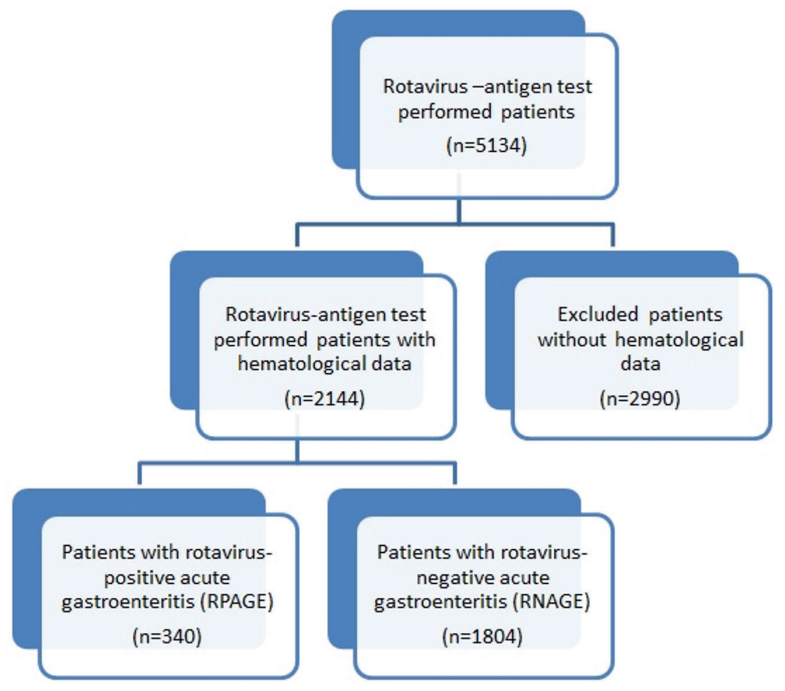

Figure 1. Enrollment algorithm of patients from the study $(n=2,990)$ (Figure 1). All children were evaluated in three different age groups: the <1-year old group, the 1-to 5-year-old group and the $>5$-year-old group. Informed consent has been received.

\section{Laboratory Assessments}

Routine $C B C$ analysis was performed from venous whole blood samples with EDTA taken from patients (Sysmex XN-1000, Sysmex R\&D Center Europe GmbH, Germany). In addition to the routine hematological parameters measured with the device, LMR, NLR and MPVPR were calculated. The diagnosis of RI was made by examining RV antigen in fresh stool samples (NADAL RV test, Germany).

\section{Statistical Analysis}

SPSS 16.0 software was used for statistical analysis. Among the continuous variables, data conforming to the normal distribution were expressed as mean \pm standard deviation. Categorical variables were specified as frequency. Comparisons of groups of continuous variables were made by t-test. ANOVA test was used to analyze the differences between groups. Pearson test was used for the analysis of categorical variables. Receiver operating characteristic analysis was performed to evaluate the diagnostic value of LMR, NLR and MPVPR in RI. $p<0.05$ was considered statistically significant.

\section{Results}

There was no statistically significant difference in terms of demographical data between RPAGE and RNAGE cases ( $p>0.05)$ (Table 1).

In the <1-year-old group, except MPVPR, the red blood cell count (RBC), hemoglobin level, hematocrit level, mean corpuscular volume (MCV), white blood cell count (WBC), neutrophil count, lymphocyte count, monocyte count,

\begin{tabular}{|c|c|c|c|c|}
\hline & & $\begin{array}{l}\text { RPAGE } \\
(\mathrm{n}=340)\end{array}$ & $\begin{array}{l}\text { RNAGE } \\
(n=1804)\end{array}$ & p \\
\hline \multirow{3}{*}{$<1$ year old } & Male & 47 & 295 & \multirow[b]{2}{*}{0.46} \\
\hline & Female & 32 & 213 & \\
\hline & $\begin{array}{l}\text { Mean age } \\
\text { (month) }\end{array}$ & $0.6 \pm 0.3$ & $0.6 \pm 0.4$ & 0.81 \\
\hline \multirow{3}{*}{$1-5$ years old } & Male & 123 & 563 & \multirow[b]{2}{*}{0.09} \\
\hline & Female & 89 & 386 & \\
\hline & $\begin{array}{l}\text { Mean age } \\
\text { (year) }\end{array}$ & $2.3 \pm 1.5$ & $2.5 \pm 1.6$ & 0.75 \\
\hline \multirow{3}{*}{$>5$ years old } & Male & 21 & 201 & \multirow[b]{2}{*}{0.52} \\
\hline & Female & 28 & 146 & \\
\hline & $\begin{array}{l}\text { Mean age } \\
\text { (year) }\end{array}$ & $9.2 \pm 2.7$ & $10.6 \pm 3.0$ & 0.08 \\
\hline
\end{tabular}


platelet count, MPV, LMR, and NLR were well matched between study groups (Table 2). In the $<1$-year-old group RPAGE cases; the cut-off value of MPVPR was 0.023 , the area under the curve (AUC) was 0.44 (0.37-0.51), sensitivity and specificity were $60 \%$ and $32 \%$, respectively. There was no difference between LMR and NLR rates in this age group (Figure $2 \mathrm{~A}$ ).

In the 1-to 5-year-old group, while the RBC, hemoglobin level and hematocrit level were statistically significantly higher in RPAGE cases, MCV was low. The WBC, monocyte count and platelet count were similar between RPAGE and RNAGE cases. While the neutrophil count and NLR were statistically significantly higher in RPAGE cases, MPV, LMR, and MPVPR were low (Table 3). In the 1-to 5-year-old group RPAGE cases; the cut-off value of MPVPR was 0.026, AUC was $0.42(0.38-0.46)$, sensitivity and specificity were

\begin{tabular}{|l|l|l|l|}
\hline \multicolumn{4}{|l|}{ Table 2. Hematological parameters of the <1-year-old group } \\
\hline & $\begin{array}{l}\text { RPAGE } \\
(\mathbf{n}=79)\end{array}$ & $\begin{array}{l}\text { RNAGE } \\
\text { (n=508) }\end{array}$ & $\mathbf{p}$ \\
\hline RBC (1012/L) & $4.39 \pm 0.73$ & $4.25 \pm 0.71$ & 0.13 \\
\hline Hemoglobin (g/dL) & $11.48 \pm 2.21$ & $11.39 \pm 2.27$ & 0.73 \\
\hline Hematocrit (\%) & $33.92 \pm 6.01$ & $33.44 \pm 6.32$ & 0.50 \\
\hline MCV (fL) & $78.22 \pm 11.65$ & $79.13 \pm 10.16$ & 0.91 \\
\hline WBC (109/L) & $11.51 \pm 5.89$ & $12.20 \pm 6.27$ & 0.34 \\
\hline Neutrophil (109/L) & $4.80 \pm 3.62$ & $5.08 \pm 4.26$ & 0.54 \\
\hline Lymphocyte (109/L) & $4.70 \pm 2.82$ & $5.27 \pm 2.95$ & 0.10 \\
\hline Monocyte (109/L) & $1.35 \pm 0.79$ & $1.44 \pm 0.94$ & 0.37 \\
\hline Platelet (109/L) & $391.25 \pm 151.42$ & $368.76 \pm 145.06$ & 0.22 \\
\hline MPV (fL) & $9.60 \pm 0.67$ & $9.74 \pm 0.92$ & 0.12 \\
\hline $\begin{array}{l}\text { Lymphocyte/ } \\
\text { monocyte ratio }\end{array}$ & $4.22 \pm 3.06$ & $4.66 \pm 3.68$ & 0.25 \\
\hline $\begin{array}{l}\text { Neutrophil/ } \\
\text { lymphocyte ratio }\end{array}$ & $1.70 \pm 1.90$ & $1.52 \pm 3.12$ & 0.50 \\
\hline MPV/platelet ratio & $0.028 \pm 0.014$ & $0.032 \pm 0.026$ & $0.04 \#$ \\
\hline $\begin{array}{l}\text { "The RPAGE group was compared with the RNAGE group (t-test) } \\
\text { RPAGE: Rotavirus-positive acute gastroenteritis, RNAGE: Rotavirus-negative acute } \\
\text { gastroenteritis, MPV: Mean platelet volume, } \\
\text { WBC: White blood cell, RBC: Rean blood cell) }\end{array}$ & \\
\hline
\end{tabular}
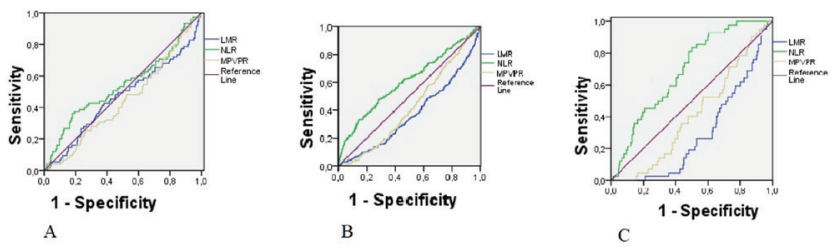

Figure 2. ROC curves of $L M R, N L R$, and MPVPR values in patients with RPAGE A. <1-year-old group, B. 1-to 5- year-old group, C. $>$ 5-year-old group

ROC: Receiver operating characteristic, LMR: Lymphocyte/ monocyte ratio, NLR: Neutrophil/lymphocyte ratio, MPVPR: Mean platelet volume/platelet ratio, RPAGE: Rotavirus positive acute gastroenteritis
$62 \%$ and $32 \%$, respectively. The cut-off value of LMR was 1.99, AUC was $0.37(0.32-0.41)$, sensitivity and specificity were $55 \%$ and $26 \%$, respectively, and the cut-off value of NLR was 1.41, AUC was 0.61 (0.56-0.65), sensitivity and specificity were $70 \%$ and $40 \%$, respectively, in this age group with RPAGE (Figure $2 \mathrm{~B}$ ).

In the >5-year-old group, the RBC, hemoglobin level, and hematocrit level were statistically significantly higher in RPAGE cases. There was no statistically significant difference among the WBC, monocyte count, platelet count, MPV, and MCV between RPAGE and RNAGE cases. While the neutrophil count and NLR were statistically significantly higher in RPAGE cases, LMR and MPVPR were low (Table 4). In the >5-year-old group RPAGE cases; the cut-off value of MPVPR was 0.032, AUC was 0.41 (0.330.49 ), sensitivity and specificity were $64 \%$ and $30 \%$, respectively. The cut-off value of LMR was 0.96, AUC was $0.29(0.22-0.36)$, sensitivity and specificity were $69 \%$ and $26 \%$, respectively, and the cut-off value of NLR was 3.79, AUC was 0.69 (0.61-0.76), sensitivity and specificity were $81 \%$ and $53 \%$, respectively, in this age group with RPAGE (Figure $2 \mathrm{C}$ ).

\begin{tabular}{|c|c|c|c|}
\hline & $\begin{array}{l}\text { RPAGE } \\
(\mathrm{n}=212)\end{array}$ & $\begin{array}{l}\text { RNAGE } \\
(n=949)\end{array}$ & $\mathrm{p}$ \\
\hline $\operatorname{RBC}\left(10^{12} / L\right)$ & $4.72 \pm 0.42$ & $4.50 \pm 0.67$ & $0.001^{\#}$ \\
\hline Hemoglobin (g/dL) & $11.82 \pm 1.01$ & $11.56 \pm 1.56$ & $0.02^{\#}$ \\
\hline Hematocrit (\%) & $34.64 \pm 2.69$ & $33.84 \pm 4.28$ & $0.01^{\#}$ \\
\hline $\operatorname{MCV}(f L)$ & $73.58 \pm 4.77$ & $75.68 \pm 6.47$ & $0.001^{\#}$ \\
\hline WBC $\left(10^{9} / L\right)$ & $10.67 \pm 4.52$ & $10.76 \pm 8.61$ & 0.83 \\
\hline Neutrophil $\left(10^{9} / \mathrm{L}\right)$ & $6.96 \pm 4.34$ & $6.07 \pm 4.39$ & $0.007^{\#}$ \\
\hline Lymphocyte $\left(10^{9} / \mathrm{L}\right)$ & $2.61 \pm 1.97$ & $3.18 \pm 2.06$ & $0.001^{\#}$ \\
\hline Monocyte $\left(10^{9} / \mathrm{L}\right)$ & $1.05 \pm 0.44$ & $1.06 \pm 1.54$ & 0.80 \\
\hline Platelet $\left(10^{9} / \mathrm{L}\right)$ & $331.57 \pm 101.28$ & $300.49 \pm 125.83$ & 0.22 \\
\hline MPV (fL) & $9.21 \pm 0.75$ & $9.35 \pm 0.95$ & $0.01^{\#}$ \\
\hline $\begin{array}{l}\text { Lymphocyte/ } \\
\text { monocyte ratio }\end{array}$ & $2.75 \pm 2.23$ & $3.96 \pm 5.02$ & $0.001^{\#}$ \\
\hline $\begin{array}{l}\text { Neutrophil/ } \\
\text { lymphocyte ratio }\end{array}$ & $5.03 \pm 5.93$ & $2.89 \pm 3.64$ & $0.002^{\#}$ \\
\hline MPV/platelet ratio & $0.031 \pm 0.016$ & $0.042 \pm 0.052$ & $0.001^{\#}$ \\
\hline
\end{tabular}

\section{Discussion}

It may not always be possible to reach specific serological detection tests used in the diagnosis of RI. The use of more accessible and cheaper hematological parameters may provide advantages in the identification 
Table 4. Hematological parameters of the $>5$-year-old group

\begin{tabular}{|l|l|l|l|}
\hline & $\begin{array}{l}\text { RPAGE } \\
\text { ( } \mathbf{n}=49)\end{array}$ & $\begin{array}{l}\text { RNAGE } \\
\text { ( }=3477)\end{array}$ & $\mathbf{p}$ \\
\hline RBC $\left(10^{12} / \mathrm{L}\right)$ & $4.86 \pm 0.65$ & $4.28 \pm 0.97$ & $0.005^{\#}$ \\
\hline Hemoglobin (g/dL) & $13.17 \pm 1.46$ & $11.70 \pm 2.28$ & $0.001^{\#}$ \\
\hline Hematocrit $(\%)$ & $38.06 \pm 3.75$ & $34.23 \pm 6.38$ & $0.001^{\#}$ \\
\hline MCV (fL) & $78.94 \pm 7.43$ & $81.18 \pm 8.66$ & 0.07 \\
\hline WBC $\left(10^{9} / \mathrm{L}\right)$ & $10.17 \pm 4.72$ & $9.69 \pm 12.39$ & 0.63 \\
\hline Neutrophil $\left(10^{9} / \mathrm{L}\right)$ & $8.33 \pm 4.36$ & $6.18 \pm 4.86$ & $0.004^{\#}$ \\
\hline Lymphocyte $\left(10^{9} / \mathrm{L}\right)$ & $1.14 \pm 0.54$ & $1.78 \pm 1.86$ & $0.02^{\#}$ \\
\hline Monocyte $\left(10^{9} / \mathrm{L}\right)$ & $0.87 \pm 0.32$ & $0.80 \pm 0.61$ & 0.22 \\
\hline Platelet $\left(10^{9} / \mathrm{L}\right)$ & $256.44 \pm 95.63$ & $230.92 \pm 177.80$ & 0.15 \\
\hline MPV (fL) & $9.68 \pm 0.66$ & $9.85 \pm 1.09$ & 0.15 \\
\hline $\begin{array}{l}\text { Lymphocyte/monocyte } \\
\text { ratio }\end{array}$ & $1.40 \pm 0.70^{\#}$ & $3.37 \pm 5.17$ & $0.001^{\#}$ \\
\hline $\begin{array}{l}\text { Neutrophil/lymphocyte } \\
\text { ratio }\end{array}$ & $9.40 \pm 6.93^{\#}$ & $6.07 \pm 8.01$ & $0.005^{\#}$ \\
\hline MPV/platelet ratio & $0.041 \pm 0.019^{\#}$ & $0.079 \pm 0.102$ & $0.001^{\#}$ \\
\hline $\begin{array}{l}\text { "The RPAGE group was compared with the RNAGE group (t-test) } \\
\text { RPAGE: Rotavirus-positive acute gastroenteritis, RNAGE: Rotavirus-negative acute } \\
\text { gastroenteritis, MPV: Mean platelet volume, MCV: Mean corpuscular volume, } \\
\text { WBC: White blood cell, RBC: Red blood cell }\end{array}$ \\
\hline
\end{tabular}

of RI. Many studies show that NLR, LMR, and platelet/ lymphocyte ratios are used in the evaluation of morbidity and mortality in critical diseases due to bacterial, viral infections, and sepsis were evaluated in a meta-analysis and the importance of these new markers was emphasized (10). There are also studies supporting the use of these markers in cancer patients and coronary diseases $(11,12)$.

It is known that lymphopenia can be a good predictor of bacterial infections, and both lymphocyte and neutrophil count should be considered rather than WBC in adult patients with suspected bacteremia (13). Monocytes, an essential component of peripheral blood, are considered an indicator of systemic inflammation (14). The lymphocyte/ monocyte ratio, a new inflammatory biomarker, is more sensitive in showing the balance between lymphocytes and monocytes (15). While the ratio of lymphocytes, which play a critical role in destroying viruses, is expected to increase in traditional viral infections, the opposite may occur in some viral diseases $(16,17)$. Also, leukocyte subgroups in peripheral blood in infections may show agerelated variability (10).

Proinflammatory cytokines cause an increase in cytoplasm volume of platelet cells in patients with the inflammatory condition. But these large platelet cells rapidly migrate to the site of inflammation where they undergo activation, and MPV may drop in proceeding inflammation $(18,19)$. There are data in the literature about changes of platelets and MPV in inflammatory processes and neoplastic diseases and its possible role as a biomarker $(20,21)$.
In childhood, the platelet count and MPV have been recognized as a hematological marker, and their roles were demonstrated in various conditions such as severe sepsis in children (22), patent ductus arteriosus in preterm infants (23), and sepsis in very low birth weight neonates (24). Some studies evaluated the prognostic value of NLR (25) and LMR (26) in retinopathy of prematurity. Most of these studies conducted <1-year-old age belong to the neonatal period. The $<1$-year-old subgroup in our study has a large number of cases that examined the entire 0-12-month period.

Children less than 1-year-old are at high risk for both developing RI and complications (27). The use of easily accessible new hematological parameters in the differential diagnosis of RI becomes more valuable in this age group.

Fei et al. (16) reported that high MPVPR can be used as an indicator in patients $<6$ years of age with influenza A infection. In another study, it was found that the lymphocyte count, platelet count, and LMR were lower, the NLR and MPVPR were higher in children with influenza infection (28). In the study of Mete et al. (20) a constant decrease in MPV was found in RPAGE and RNAGE cases compared to the healthy control group, and it was stated that MPV acted as a negative acute phase reactant. In our study, MPV was low only in the 1-to 5-year-old group with RPAGE. Besides, MPVPR was statistically significantly lower in RPAG cases in all age groups.

A study in RPAGE patients less than five years of age found a decrease in the lymphocyte count and MPV, an increase in the neutrophil count and monocyte count. In the same study, it was stated that low LMR and high NLR could indicate RI in children with AGE (29). In another study conducted in a group of pediatric patients $<36$ months old, an increase in NLR was found in acute pyelonephritis cases together with other acute phase reactants (30). In our study, MPV was similarly low in the 1-to 5-year-old group RPAGE cases, but it was not observed any difference in the $<1$-year old group or the $>5$-year-old group RPAGE cases.

In the present study, the neutrophil count and NLR were higher, while the lymphocyte count and LMR were lower in patients with RPAGE over 1 year of age.

\section{Study Limitations}

Our present study has some limitations. It could not be reached enough data to determine the clinical severity of gastroenteritis in patients. RNAGE cases have not been differentially diagnosed with other infectious agents. It should be noted that these limitations arise due to the retrospective nature of our study. Despite all these limitations, it is thought that our study will make important contributions to the literature as it provides 
the opportunity to evaluate a large number of patients in different age groups separately.

\section{Conclusion}

New hematological parameters may potentially useful for the identification of RI in childhood. The present study emphasized that low MPVPR can be used as a biomarker in the differential diagnosis of RI in all age groups. It was shown that low LMR and high NLR had a predictive value for RI in children older than one year of age, but further studies are needed for children the $<1$-year-old.

\section{Authorship Contributions}

Concept: M.A.O., H.T., M.O., Design: M.A.O., H.T., M.O., Data Collection or Processing: M.A.O., H.T., A.I.T., Analysis or Interpretation: M.A.O., H.T., M.O., A.I.T., Literature Search: M.A.O., H.T., Writing: M.A.O., H.T., M.O., A.I.T.

Conflict of Interest: No conflict of interest was declared by the authors.

Financial Disclosure: The authors declared that this study received no financial support.

\section{References}

1. Gupta RK, Vajpayee S, Agrawal R, Goyal AK, Nair NP, Thiyagarajan V. Vaccination Epidemiology and Genotyping of Rotavirus Gastroenteritis at a Tertiary Care Centre of NorthEast Rajasthan. Indian J Pediatr 2021;88:90-6.

2. Jin Kim AH, Hogarty MP, Harris VC, Baldridge MT. The Complex Interactions Between Rotavirus and the Gut Microbiota. Front Cell Infect Microbiol 2021;10:586751.

3. Mwenyenkulu TE, Ntenda PAM. Effectiveness of rotavirus vaccine in preventing transmission of rotavirus from children to household contacts in Malawi. Lancet Infect Dis 2021;21:590-1.

4. Badur S, Öztürk S, Pereira P, et al. Systematic review of the rotavirus infection burden in the WHO-EMRO region. Hum Vaccin Immunother 2019;15:2754-68.

5. Ghaswalla PK, D'Angelo J, Abu-Elyazeed R. Rotavirus vaccination in the US: a systematic review of vaccination coverage and completion. Hum Vaccin Immunother 2021;17:872-9.

6. Kyo K, Takano C, Kasuga $Y$, et al. Severe rotavirus gastroenteritis in children older than 5 years after vaccine introduction. J Infect Chemother 2021;27:598-603.

7. Quintero-Ochoa G, Romero-Argüelles R, Aviles-Hernández $A$, et al. Viral agents of gastroenteritis and their correlation with clinical symptoms in rotavirus-vaccinated children. Infect Genet Evol 2019;73:190-6.

8. Jiang Y, Mingcui Zang M, Li S. Serum PLR and LMR in Behçet's disease: Can they show the disease activity? Medicine (Baltimore) 2017;96:e6981.
9. Temel $H$, Gündüz $M$, Tosun Al, Celebi $M$, Okur $M$. The Importance of Neutrophi/Lymphocyte and Lymphocyte/ Monocyte Ratios in The Diagnosis of Influenza in Children. Clin Lab 2021:67.

10. Russell CD, Parajuli A, Gale HJ, et al. The utility of peripheral blood leucocyte ratios as biomarkers in infectious diseases: a systematic review and meta analysis. J Infect 2019;78:339-48.

11. Kose N, Akin F, Yildirim T, Ergun G, Altun I. The association between the lymphocyte-tomonocyte ratio and coronary artery disease severity in patients with stable coronary artery disease. Eur Rev Med Pharmacol Sci 2019;23:2570-5.

12. Li KJ, Xia XF, Su M, Zhang H, Chen WH, Zou CL. Predictive value of lymphocyte-to-monocyte ratio (LMR) and neutrophilto-lymphocyte ratio (NLR) in patients with oesophageal cancer undergoing concurrent chemoradiotherapy. BMC Cancer 2019;19:1004.

13. Wyllie DH, Bowler ICJW, Peto TEA. Relation between lymphopenia and bacteraemia in UK adults with medical emergencies. J Clin Pathol 2004;57:950-5.

14. Shi C, Pamer EG. Monocyte recruitment during infection and inflammation. Nat Rev Immunol 2011;11:762-74.

15. Li J, Jiang R, Liu WS, et al. A large cohort study reveals the association of elevated peripheral blood lymphocyte-tomonocyte ratio with favorable prognosis in nasopharyngeal carcinoma. PLoS One 2013;8:e83069.

16. Fei $Y$, Zhang $H$, Zhang C. The application of lymphocyte, platelet and mean platelet volume/platelet ratio in influenza A infection in children. J Clin Lab Anal 2019;33:e22995.

17. Coskun $O$, Avci IY, Sener $K$, et al. Relative lymphopenia and monocytosis may be considered as a surrogate marker of pandemic influenza a (H1N1). J Clin Virol 2010;47:388-9.

18. Senchenkova EY, Komoto S, Russell J, et al. Interleukin-6 mediates the platelet abnormalities and thrombogenesis associated with experimental colitis. Am J Pathol 2013;183:173-81.

19. Afsar N, Afroze IH, Tahniath $H$, Abid Z. Role of mean platelet volume as an adjunct in evaluation of acute inflammation. Annals of Pathology and Laboratory Medicine 2017;4:466-9.

20. Mete E, Akelma AZ, Cizmeci MN, Bozkaya D, Kanburoglu MK. Decreased mean platelet volume in children with acute rotavirus gastroenteritis. Platelets 2014;25:51-4.

21. Korniluk A, Koper-Lenkiewicz OM, Kamińska J, Kemona H, Dymicka-Piekarska V. Mean Platelet Volume (MPV): New Perspectives for an Old Marker in the Course and Prognosis of Inflammatory Conditions. Mediators Inflamm 2019;17:9213074.

22. Sayed SZ, Mahmoud MM, Moness HM, Mousa SO. Admission platelet count and indices as predictors of outcome in children with severe Sepsis: a prospective hospital-based study. BMC Pediatr 2020;20:387.

23. Ding R, Zhang Q, Duan $Y$, Wang $D$, Sun Q, Shan R. The relationship between platelet indices and patent ductus 
arteriosus in preterm infants: a systematic review and metaanalysis. Eur J Pediatr 2020;19:699-708.

24. Guida JD, Kunig AM, Leef KH, McKenzie SE, Paul DA. Platelet count and sepsis in very low birth weight neonates: is there an organism specific response? Pediatrics 2003;111:1411-5.

25. Kurtul BE, Kabatas EU, Zenciroglu A, et al. Serum neutrophilto-lymphocyte ratio in retinopathy of prematurity. J AAPOS 2015;19:327-31.

26. Hu $Y X, X u X X$, ShaoY, et al. The prognostic value of lymphocyte-to-monocyte ratio in retinopathy of prematurity. Int J Ophthalmol. 2017;10:1716-21.

27. Misra S, Sabui TK, Basu S, Pal N. A prospective study of rotavirus diarrhea in children under 1 year of age. Clin Pediatr (Phila) 2007;46:683-8.
28. Zhu R, Chen C, Wang Q, Zhang X, Lu C, Sun Y. Routine blood parameters are helpful for early identification of influenza infection in children. BMC Infect Dis 2020;20:864-74.

29. Zhang C, Li G, Zhang H, Zhang H, Fei Y. Decreased Lymphocyte to Monocyte Ratio and Increased Neutrophil to Lymphocyte Ratio Observed in Rotavirus-Positive Acute Gastroenteritis in Children: A Retrospective Study. Ann Clin Lab Sci 2020;50:450-6.

30. Han SY, Lee IR, Park SJ, Kim JH, Shin JI. Usefulness of neutrophil-lymphocyte ratio in young children with febrile urinary tract infection. Korean J Pediatr 2016;59:139-44. 